\title{
Theoretical Properties Prediction of Diesel-Biodiesel-DEE Blend as a Fuel for C.I. Engine With Required Modifications for Optimum Performance
}

\author{
Sushant Shinde ${ }^{+*}$ and S. D. Yadav ${ }^{\dagger}$ \\ †Automobile Engineering Department, Shivaji University Kolhapur, Maharashtra, India \\ Accepted 01 Sept 2016, Available online 02 Sept 2016, Vol.6, No.5 (Oct 2016)
}

\begin{abstract}
The reduction in vehicular exhaust emissions with high engine performance are measure concern regarding engine design. To control exhaust emissions of internal combustion engine the governmental \& environmental agencies implemented stringent emission norms. These stringent emission norms are very difficult to achieve through advance engine technologies. Also rapid depletion of petroleum based fuels with increasing prices is measure issue now-adays. Hence the interest of researchers increases towards the development of renewable alternative fuels for I.C. engine the renewable fuels having capacity to reduce emissions than petroleum based fuel. Diethyl ether is one of the promising renewable fuels which reduce the exhaust harmful emissions with improved performance parameters. The $D E E$ is promising alternative fuel for C.I. engine obtained from dehydration process of ethanol. Many researchers investigated the suitability of DEE as an alternative fuel for C.I. engine without any modifications with limited percentage of DEE in diesel \& biodiesel. The aim of this research work is to improve the C.I. engine performance with required modifications for diesel-biodiesel-DEE blended fuel.
\end{abstract}

Keywords: Diethyl Ether, Alternative Fuel, Properties, Modifications

\section{Introduction}

As compared to petrol engine, diesel engines are widely used in worldwide as a prime mover because of its high thermal efficiency, high torque capacity, low $\mathrm{HC} \& \mathrm{CO}$ emission etc. So diesel engines cannot replace by any other prime mover in near future. Various technologies are being developed to face the problem of depleting resources of petroleum fuel \& lower emissions like EGR technology, CRDI system, HCCI \& PCCI combustion technology, duel fuel injection etc. Using these various engine \& combustion technologies stringent emission norms cannot be meet. Biodiesel, ethanol, methanol, vegetable oils, LPG, CNG etc. are the various renewable alternative fuels are being used to meet the stringent emission norms \& improve engine performance. These alternative fuels having some disadvantages like high viscosity, low cetane number, storage problem, low energy density, safety requirement \& miscibility limit with diesel.

Ethanol is one of the promising high oxygen contained alternative fuel. But it has many obstacles to use in C.I engine because of low cetane number (Istvan et al, 2011), poor combustion characteristics \&limited miscibility with diesel fuel. To overcome these

*Corresponding author: Sushant Shinde problems, ethanol can be converted easily into DEE through a dehydration process. DEE has several favorable properties for CI engines such as high cetane number $(>125)$, low auto ignition temperature, high oxygen content, reasonable energy density for onboard storage, broad flammability limits, high miscibility with diesel fuel and renewable bio-fuel. DEE is a pungent, volatile, highly flammable liquid and widely used as a common solvent. It is the simplest ether expressed by its chemical formula $\mathrm{CH}_{3} \mathrm{CH}_{2}-\mathrm{O}-$ $\mathrm{CH}_{2} \mathrm{CH}_{3}$, consisting of two ethyl groups bonded to a central oxygen atom as shown in Fig. 1. (Patil \& Thipse, 2015)

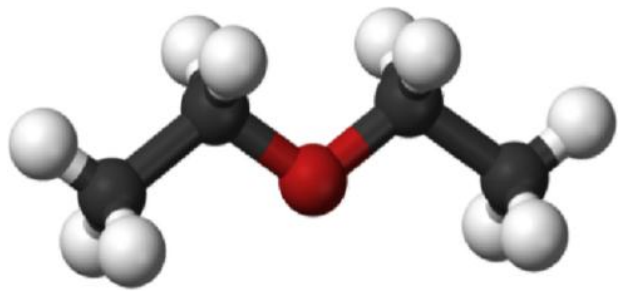

Fig.1 Chemical Structure of DEE Molecule

The national renewable energy laboratory (NREL) conducted a process simulation exercise which showed that hydrous ethanol (ethanol diluted with water) can be converted to DEE. The main reactions is, 


$$
\begin{aligned}
& \underset{\text { Ethanol }}{2 \mathrm{C}_{2} \mathrm{H}_{5} \mathrm{OH}} \rightarrow \underset{\text { DEE }}{\left(\mathrm{C}_{2} \mathrm{H}_{5}\right)_{2} \mathrm{O}}+\mathrm{H}_{2} \mathrm{O} \\
& \text { Ethel }
\end{aligned}
$$

The simulation also showed that the resulting liquid phase of water-ethanol/ ethanol-DEE could be separated in simple decanter separator. Ideally hydrous ethanol would be generated at the end of biomass ethanol production process so that the ether conversion process would take place before the final distillation in that process. The total process is simulated in fig. 2 .

The simulation also showed that the resulting liquid phase of water-ethanol/ ethanol-DEE could be separated in simple decanter separator. Ideally hydrous ethanol would be generated at the end of biomass ethanol production process so that the ether conversion process would take place before the final distillation in that process. The total process is simulated in fig. 2 .

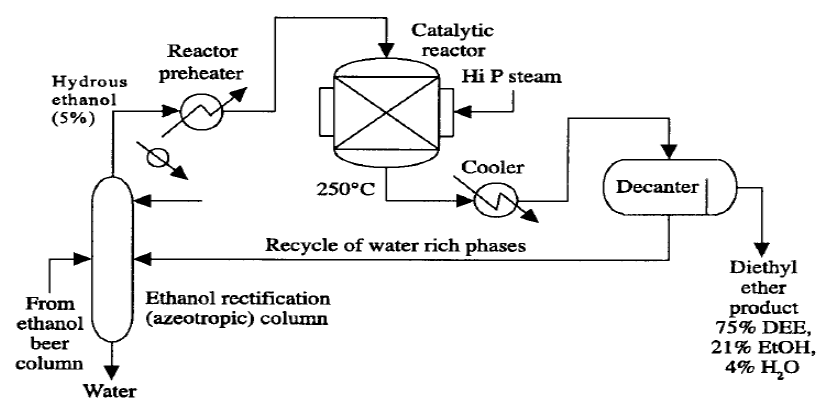

Fig.2 Production of DEE from Ethanol

\section{Literature Review}

The physical \& chemical properties of DEE are good from emission \& performance point of view in C.I. engine. Many researchers studied theoretically \& experimentally the suitability if DEE as fuel for diesel engine. The experiment was carried out to investigate the effect of DEE with diesel-kerosene blend. It is found that optimum performance \& emission levels achieved at $15 \%$ of DEE in diesel-kerosene blend. Even though DEE has high cetane number the ignition delay of diesel-DEE blends higher as compared to diesel. Also as the percentage of DEE to diesel-kerosene blend increases, the kinematic viscosity, density, calorific value of blend decreases \& cetane number, oxygen content increased (Patil \& Thipse, 2015). In the study of effect of DEE with neem oil biodiesel it is found that $\mathrm{CO} \&$ smoke emission were reduced while $\mathrm{HC} \& \mathrm{NO}_{\mathrm{x}}$ emissions were increased for 5\% DEE blended fuel. Also BSFC \& brake thermal efficiency were improved for DEE-biodiesel blend. Up to $5 \%$ of DEE is promising technique (S. Sivalakshmi \& T. Balusamy, 2013). In the experimental evaluation of performance \& emission characteristics of diesel engine using diesel-DEE blend it is found that as the percentage of DEE in blend increases, the smoke, $\mathrm{NO}_{\mathrm{x}} \& \mathrm{CO}$ emissions goes on decreasing with increased $\mathrm{HC}$ emission. Regarding performance point of view addition of DEE to diesel increases BSFC with constant brake thermal efficiency. Hence blending of DEE to diesel up to high blending ratio is advantageous from both emission \& performance point of view (D. C. Rakopoulos et al, 2012). The effect of DEE \& waste plastic pyrolysis oil on C.I. engine investigated experimentally. It is concluded that addition of DEE as an oxygenated fuel improves performance parameters \& reduce tail pipe emission levels (J. Devaraj et al, 2015). The experimentally comparison between the effects of various percentage of DEE to biodiesel on combustion, performance $\&$ emission parameters of diesel engine is carried out to analyze the potential of DEE. It is reported that up to 20\% DEE in biodiesel gives better stability with reduction in smoke \& $\mathrm{NO}_{\mathrm{X}}$ emissions. Also HC \& CO emissions were slightly higher as compared to biodiesel. Hence up to $10-20 \%$ of DEE as an oxygenated fuel can be added as an alternative fuel to biodiesel (S. Sudhakar \& Dr. S. Shivprakasam, 2014).

From literature review it is found that up to 10 $15 \%$ of DEE-diesel blend gives best results from emission \& performance point of view. Above $15 \%$ of DEE in diesel results in poor performance or instable operation \& power output of C.I. engine. It is due to high volatility, lower kinematic viscosity \& density of DEE. This leads to vapor lock \& increased leakage in fuel system. This can be resolved by addition of biodiesel to diesel-DEE blend (Patil \& Thipse, 2015), (Istvan et al, 2011).

The main purpose of this investigation is to find out optimum blending ratio according to ASTM D975 standards. Also it is desired to find out modifications required in conventional diesel engine using dieselbiodiesel-DEE blend.

\section{Attractive Properties of DEE}

There are number of physical \& chemical properties of fuels which having direct impact of performance \& emission parameters of diesel engine. The various physiochemical properties of diesel, biodiesel \& DEE compared in table 1.

\subsection{Cetane Number}

Cetane number is a primary indicator of easy in selfignition of fuel. Cetane no is an important property associated with ignition delay. High cetane number shows the good auto ignition quality of compression ignition fuel with lower ignition delay. Cetane number of DEE is very high (125>) as compared to various compression ignition fuels.

\subsection{Oxygen content}

The addition of oxygen content additive to diesel is one of the promising techniques to reduce soot formation inside the combustion chamber. Oxygen content of DEE is high ( $21.6 \%$ by mass) as compared to diesel \& diesel ethanol blend. Addition of oxygen to fuel results more complete combustion of fuel \& reduces harmful toxic emission. 
Table 1 Physicochemical Properties of Diesel, Biodiesel \& DEE

\begin{tabular}{|c|c|c|c|}
\hline Properties & Diesel & Biodiesel & DEE \\
\hline Chemical Structure & $\mathrm{C}_{10}-\mathrm{H}_{25}$ & $\mathrm{C}_{12}-\mathrm{H}_{22}$ & $\mathrm{C}_{2} \mathrm{H}_{5}-\mathrm{O}-\mathrm{C}_{2} \mathrm{H}_{5}$ \\
\hline $\mathrm{O}_{2}$ Content (mass $\left.\%\right)$ & 0 & $10-12$ & 21.6 \\
\hline Cetane umber & 52 & 51 & $>125$ \\
\hline Auto-ignition Temp. $\left({ }^{0} \mathrm{C}\right)$ & 250 & - & 160 \\
\hline Boiling Point at 1 atm. $\left({ }^{0} \mathrm{C}\right)$ & $146-374$ & $182-337$ & 34.6 \\
\hline Lower Calorific Value $(\mathrm{MJ} / \mathrm{kg})$ & 43.26 & 39.83 & 33.9 \\
\hline A/F ratio & 14.7 & 13.8 & 11.1 \\
\hline Liquid Density at NTP $\left(\mathrm{kg} / \mathrm{m}^{3}\right)$ & 836 & 864 & 713 \\
\hline Viscosity of Liquid at NTP $(\mathrm{cSt})$ & 2.45 & 4.77 & 0.23 \\
\hline
\end{tabular}

\subsection{Auto ignition Temperature}

The temperature at which a substance can be brought to flames without any external source like spark is called auto ignition temperature. Low auto-ignition temperature leads to good combustion due to this the $\mathrm{NO}_{\mathrm{x}}$ emission is reduced. Due to low auto-ignition temperature $\left(160^{\circ} \mathrm{c}\right)$ of DEE it is also known as cold start aid fuel.

\subsection{Density}

Fuel density is mass per unit volume. As cetane number, viscosity \& heating value are strongly related with density it has direct impact on performance \& emissions parameters. The quality of atomization \& combustion depends upon density (Zayed \& Ahmed, 2014) (D. H. Qi et al, 2011). Change in fuel density affect the energy content of the fuel \& alters the air fuel ratio. As higher density fuel produces more power it is important property from fuel economy point of view.

\subsection{Viscosity}

Viscosity is a measure of a liquids resistance to flow. The quality of spry, ease of starting the engine, the size of the particles and the quality of the fuel-air mixture in combustion chamber depends upon viscosity of fuel. The viscosity of DEE is very low as compared to other conventional fuel.

\section{Predication of Properties of DEE Blends}

There are various formulas to calculate the properties of the DEE blends. As the proportion of different constituent in blend changes its properties goes on changing. The $15 \%$ of biodiesel in diesel is best blend from performance point of view. For $15 \%$ biodiesel in diesel gives lest BSFC \& BTE improved by $1.17 \%$ (Shekar \& Prabhakar, 2015). Hence DEE percentage is varied from 10 to $30 \%$ in B15 (85\% diesel \& 15\% biodiesel) blend.

\subsection{Cetane number}

$\mathrm{CN}_{\mathrm{blend}}=\sum_{i=1}^{n} C N i \times X i$
Where, $\mathrm{CN}_{\mathrm{i}}$ is the cetane number of each constituent \& $\mathrm{X}_{\mathrm{i}}$ is the \% volume of each constituent in blend.

Oxygen Content:-

$\mathrm{O}_{\text {blend }}=\frac{\sum_{i=1}^{n}(\rho \mathrm{i} \times \mathrm{Ci} \times \mathrm{Xi})}{\sum_{i=1}^{n}(\rho \mathrm{i} \times \mathrm{Xi})}$

Where, $\rho_{\mathrm{i}}$ is the density of each constituent, $\mathrm{C}_{\mathrm{i}}$ is the oxygen content of each constituent \& $X_{i}$ is the $\%$ volume of each constituent in blend.

\subsection{Density}

$\rho_{\text {blend }}=\sum_{i=1}^{n}\left(\rho i \times X_{i}\right)$

Where, $\rho_{\mathrm{i}}$ is the density of each constituent \& $\mathrm{X}_{\mathrm{i}}$ is the $\%$ volume of each constituent in blend.

\subsection{Lower Calorific value}

$\mathrm{CV}_{\text {blend }}=\frac{\sum_{i=1}^{n}(\rho \mathrm{i} \times \mathrm{Xi} \times \mathrm{CVi})}{\sum_{i=1}^{n}(\rho \mathrm{i} \times \mathrm{Xi})}$

Where, $\mathrm{CV}_{\mathrm{i}}$ is the lower calorific value of each constituent, $\rho_{\mathrm{i}}$ is the density of each constituent \& $\mathrm{X}_{\mathrm{i}}$ is the \% volume of each constituent in blend.

\subsection{Kinematic Viscosity}

$\ln \mu_{\mathrm{blend}}=\sum_{i=1}^{n} X i \times \ln \mu i$

Where, $\mu_{\mathrm{i}}$ is the kinematic viscosity of each constituent $\& \mathrm{X}_{\mathrm{i}}$ is the \% volume fraction of each constituent in blend.

The table 2 shows the important properties of the blends of DEE with diesel \& biodiesel. In this work properties are calculated for various percentage of diesel-biodiesel-DEE blends. From table D denotes for pure diesel, BD denotes for pure biodiesel \& DEE denotes for DEE.

According to diesel fuel requirement of auto fuel vision and policy 2025 government of India report \& ASTM D975 standard 35\% diesel, 20\% DEE \& 45\% biodiesel gives optimum blending ratio. For optimum blend ratio the as compared to pure diesel cetane number increased by $27.21 \%$, oxygen content increased from 0 to $14.57 \%$ by mass which is advantageous from better combustion point of view. 
Table 2 Properties of diesel-biodiesel-DEE blends

\begin{tabular}{|c|c|c|c|c|c|}
\hline Fuel & $\mathrm{CN}$ & $\mathrm{O}_{2}$ Cont. & Density & $\begin{array}{c}\text { Low. Cal. } \\
\text { Value }\end{array}$ & $\begin{array}{c}\text { Viscosit } \\
\mathrm{y}\end{array}$ \\
\hline Diesel & 52 & 0 & 836 & 43.26 & 2.45 \\
\hline Biodiesel & 51 & 12 & 864 & 39.83 & 4.77 \\
\hline Diethyl Ether & 125 & 21.6 & 713 & 33.9 & 0.23 \\
\hline D75BD15DE10 & 59.2 & 3.7 & 827.9 & 41.91 & 2.13 \\
\hline D70BD15DE15 & 62.8 & 4.7 & 821.75 & 41.5 & 1.89 \\
\hline D65BD15DE20 & 66.5 & 5.7 & 815.6 & 41.07 & 1.68 \\
\hline D60BD15DE25 & 70.0 & 6.7 & 809.45 & 40.64 & 1.49 \\
\hline D55BD15DE30 & 73.8 & 7.7 & 803.3 & 40.2 & 1.33 \\
\hline D35BD40DE20 & 66.2 & 14.57 & 824 & 40.02 & 2.06 \\
\hline
\end{tabular}

The decrease in density, lower calorific value \& kinematic viscosity of the blend by $1.43 \%, 7.48 \%$, \& $15.91 \%$ respectively for optimum blend ratio as compared to pure diesel. The reduced viscosity is advantageous from atomization point of view.

\section{Stoichiometric Air Fuel Ratios}

For complete combustion of a fuel the required minimum amount of air is called stoichiometric air or also called theoretical air.

\subsection{Stoichiometric $A / F$ for Diesel}

The chemical formula for petroleum diesel is ranging from $\mathrm{C}_{10} \mathrm{H}_{20}$ to $\mathrm{C}_{15} \mathrm{H}_{28}$. The average chemical formula for common diesel is $\mathrm{C}_{12} \mathrm{H}_{23}$. The combustion equation for diesel fuel is as,

$\mathrm{C}_{12} \mathrm{H}_{23}+17.75\left(\mathrm{O}_{2}+3.76 \mathrm{~N}_{2}\right) \rightarrow 12 \mathrm{CO}_{2}+11.5 \mathrm{H}_{2} \mathrm{O}+63.9 \mathrm{~N}_{2}$

The required amount air for combustion is 17.75 moles of oxygen \& 17.75 x 3.76 moles of nitrogen, giving a total of 84.49 moles of air per mole of fuel. On mass basis the air fuel (AF) ratio for above combustion reaction is,

$\mathrm{AF}=\frac{\text { Mass of air }}{\text { Mass of fuel }}$

$\mathrm{AF}=\frac{84.49 \times 28.97}{12 \times 12+23}$

$\mathrm{AF}=14.65$.

The air fuel ratio for diesel is $14.65: 1$

\subsection{Stoichiometric $A / F$ for Biodiesel}

There are two types of biodiesel that are generally used when calculating combustion equation $\mathrm{C}_{19} \& \mathrm{C}_{20}$ chain length biodiesel. The average chemical formula for biodiesel is $\mathrm{C}_{19} \mathrm{H}_{36} \mathrm{O}_{2}$. The combustion equation for biodiesel using $\mathrm{C}_{19}$ chain length is as below,

$\mathrm{C}_{19} \mathrm{H}_{36} \mathrm{O}_{2}+27\left(\mathrm{O}_{2}+3.76 \mathrm{~N}_{2}\right) \rightarrow 19 \mathrm{CO}_{2}+18 \mathrm{H}_{2} \mathrm{O}+101.52 \mathrm{~N}_{2}$

The amount of combustion air is 27 moles of oxygen \& $27 \times 3.76$ moles of nitrogen, giving a total of 128.52 moles of air per mole of fuel. On mass basis the air fuel (AF) ratio for above combustion reaction is,

$\mathrm{AF}=\frac{128.53 \times 28.97}{19 \times 12+36+16 \times 2}$

$\mathrm{AF}=13.04$

The air fuel ratio for biodiesel is $13: 1$

\subsection{Stoichiometric A/F for Diethyl Ether}

The chemical formula for diethyl ether is $\mathrm{C}_{4} \mathrm{H}_{10} \mathrm{O}$. The combustion equation for diethyl ether is,

$\mathrm{C}_{4} \mathrm{H}_{10} \mathrm{O}+6\left(\mathrm{O}_{2}+3.76 \mathrm{~N}_{2}\right) \rightarrow 4 \mathrm{CO}_{2}+5 \mathrm{H}_{2} \mathrm{O}+22.56 \mathrm{~N}_{2}$

The combustion air contains 6 moles of oxygen \& $6 x$ 3.76 moles of nitrogen, giving a total of 28.38 moles of air per mole of fuel. On mass basis the air fuel (AF) ratio for above combustion reaction is,

$\mathrm{AF}=\frac{28.38 \times 28.97}{4 \times 12+10+16}$

$\mathrm{AF}=11.18$

The air fuel ratio for DEE is 11.18:1. As compared to diesel \& biodiesel the air fuel ratio for DEE is low due to its high oxygen content.

The table 3 shows the air fuel ratios for various blends of diesel, biodiesel \& DEE. As the percentage of DEE in blend increases the air-fuel ratio goes on decreasing. As compared with pure diesel, the reduction in air fuel ratio for optimum blend is $8.33 \%$.

Table 3 Stoichiometric Air-Fuel Ratio for DieselBiodiesel-DEE Blends

\begin{tabular}{|c|c|c|}
\hline Sr. No. & Fuel Blend & $\begin{array}{c}\text { Stoichiometric A/F } \\
\text { Ratio }\end{array}$ \\
\hline 1 & Diesel (D100) & $14.7: 1$ \\
\hline 2 & Biodiesel (BD100) & $13.1: 1$ \\
\hline 3 & Diethyl Ether (DE100) & $11.18: 1$ \\
\hline 4 & D75BD15DE10 & $13.83: 1$ \\
\hline 5 & D70BD15DE15 & $13.89: 1$ \\
\hline 6 & D65BD15DE20 & $13.79: 1$ \\
\hline 7 & D60BD15DE25 & $13.69: 1$ \\
\hline 8 & D55BD15DE30 & $13.58: 1$ \\
\hline 9 & D35BD45DE20 & $13.43: 1$ \\
\hline
\end{tabular}




\section{Modifications Required}

\subsection{Compression Ratio}

The DEE has high cetane number as well as high latent heat of evaporation. It is expected that addition of DEE to diesel or biodiesel result in reduced ignition delay. But due to addition of DEE the latent heat of evaporation of blend increased which result in reduced evaporation rate \& increased ignition delay (Patil \& Thipse, 2015), (J. Devaraj et al, 2014). Various researchers had studied effect of compression ratio on performance \& emission. They reported that ignition delay reduced with increasing the compression ratio (Gnanamoorthi \& Devaradjane, 2014), (Hariram \& VageshShangar, 2015).

\subsection{Injection Timing}

Retarding or advancement in injection timing has direct impact on performance \& emission parameters of engine. Hence the conventional diesel engines have to modified for better performance \& reduced emission with optimum injection timing.

\subsection{Injection System}

The conventional fuel systems are designed for injection of fuel only. The addition of DEE to diesel increases the volatility of the blend. Due to this the vapour percentage of fuel in injector is high. The conventional injection systems are not able to deliver both the liquid \& vapour form of fuel. There is need to modify the injection system for delivering both liquid \& vapour form fuel.

\subsection{Intake system}

DEE is very high oxygen contained fuel as compared to petroleum fuel. The addition of DEE reduces the airfuel ratio of the blend. Hence intake system has to be modified for stoichiometric air fuel ratio.

\section{Conclusion}

From theoretical study it is concluded that addition of DEE to diesel and biodiesel, increases the cetane number as well as oxygen content of the blend. Also it is observed that reduction in lower calorific value, density \& kinematic viscosity. Due to high oxygen content, high cetane number \& low viscosity, as the percentage of DEE increases, the performance parameters like BTE, BSFC etc. improved with lower emissions. But the addition of DEE to diesel and biodiesel is up to $15 \%$ gives better results. Hence with required modifications in conventional diesel engine the percentage of DEE to diesel and biodiesel can be increased for better performance \& reduced emission parameters.

\section{References}

Patil K. R. \& Thipse S. S., (2015), Experimental investigation of $\mathrm{CI}$ engine combustion, performance and emissions in DEE-kerosene-diesel blends of high DEE concentration, Energy Conversion and Management, Vol. 89, pp.396-408.

Sivalakshmi S., \& Balusamy T., (2013), Effect of biodiesel and its blends with diethyl ether on the combustion, performance and emissions from a diesel engine, Fuel, Vol. 106, pp.106-110.

Rakopoulos Dimitrios C., Rakopoulos Constantine D., Evangelos G. Giakoumis, Athanasios M. Dimaratos, (2012), Characteristics of performance and emissions in highspeed direct injection diesel engine fueled with diethyl ether/diesel fuel blends, Energy, Vol. 42, pp.214-224.

J. Devaraj, Y. Robinson \& P. Ganpathi, (2015), Experimental investigation of performance, emission and combustion characteristics of waste plastic pyrolysis oil blended with diethyl ether used as fuel for diesel engine," Energy, pp.1-6.

Sudhakar \& Dr. S. Sivaprakasam, (2014), Potential of Diethyl Ether Blends with Biodiesel in DI Diesel Engine - An Experimental Investigation," International Journal of Research in Engineering \& Advanced Technology, pp.1-6.

Zayed Al-Hamamre \& Ahmed Al-Salaymeh, (2014) Physical properties of (jojoba oil + biodiesel), (jojoba oil + diesel)and (biodiesel + diesel) blends, Fuel, pp.175-188.

D. H. Qi, H. Chen, L. M. Geng,\& Y. Z. Bian, (2011) Effect of diethyl ether and ethanol additives on the combustion and emission characteristics of biodiesel-diesel blended fuel engine, Renewable Energy, pp.1252-1258.

Istvan Barabas and Ioan-Adrian Todorut, (2011), Biodiesel Quality, Standards and Properties, ISBN: 978-953-307784-0.

M. Iranmanesh , J. P. Subrahmanyam \& M. K. G. Babu, (2008), Application Of Diethyl Ether To Reduce Smoke And Nox Emissions Simultaneously With Diesel And Biodiesel Fueled Engines, ASME International Mechanical Engineering Congress and Exposition.

Auto Fuel Vision and Policy 2025, Report of the expert committee government of India, may 2014

Syntek Global Inc., ASTM D975 Diesel Fuel Specification Test.

V. Gnanamoorthi \& G. Devaradjane, 2014, "Effect of compression ratio on the performance, combustion and emission of DI diesel engine fueled with ethanol-Diesel blend," Journal of the Energy Institute, pp.1-8.

V. Hariram\& R. VageshShangar, (2015), Influence of compression ratio on combustion and performance characteristics of direct injection compression ignition engine, Alexandria Engineering Journal.

S. Saravanan, G. Nagarajan, G. Lakshmi Narayana Rao \& S. Sampath, (2014), Theoretical and experimental investigation on effect of injection timing on NOx emission of biodiesel blend, Energy, Vol. 66, pp.216-221.

N. Panneerselvam, A. Murugesan, C. Vijayakumar, A Kumaravel, D. Subramaniam \& A.Avinash, (2015), Effects of injection timing on bio-diesel fuelled engine characteristics-An overview, Renewable and Sustainable Energy Reviews, Vol.50, pp.17-31.

A. K. Agarwal, D. K. Srivastava, A. Dhar, R. K. Maurya, P. C. Shukla, A. P. Singh, (2013), Effect of fuel injection timing and pressure on combustion, emissions and performance characteristics of a single cylinder diesel engine, Fuel.

S. Hariharan, S. Murugan\& G. Nagarajan, (2013), Effect of Diethyl Ether on Tyre Pyrolysis Oil Fueled Diesel Engine, Fuel, pp.109-115.

Y. B. Mathur, M. P. Poonia, A. S. Jethoo \& R. Singh, (2012) Optimization of Compression Ratio of Diesel Fuelled Variable Compression Ratio Engine, International Journal of Energy Engineering, pp.99-101. 
Jagannath Hirkude \& Atul S. Padalkar, (2014), Experimental investigation of the effect of compression ratio on performance and emissions of $\mathrm{CI}$ engine operated with waste fried oil methyl ester blend, Fuel Processing Technology, pp.267-375.

S. M. Ashrafur Rahman, H. H. Masjuki, M. A. Kalam, A. Sanjid \& M. J. Abedin, (2014), Assessment of emission and performance of compression ignition engine with varying injection timing, Renewable and Sustainable Energy Reviews, pp.221-230.

Arun Kumar Wamankar \& S. Murugan, (2014), Effect of injection timing on a DI diesel engine fuelled with a synthetic fuel blend, Journal of the Energy Institute, pp.1-8.

A.Vignesh Moorthy pandian, (2014), Experimental Analysis of Performance and Emission of Diesel Blends with Pongamina Biodiesel and Diethyl Ether, Journal of Chemical and Pharmaceutical Sciences, pp.273-274.

Obed M. Ali, Rizalman Mamat \& Che Ku M. Faizal, (2013), Effects of Diethyl Ether Additives on Palm Biodiesel Fuel Characteristics and Low Temperature Flow Properties, International Journal of Advanced Science and Technology, pp.111-120.
Kallu. Raja Sekhar \& G.V.N.B.Prabhakar, (2015), Optimization Of Biodiesel Blend Ratio For Compression Ignition Engine, International Journal in IT and Engineerin

Ismet Sezer, (2011), Thermodynamic, performance and emission investigation of a diesel engine running on dimethyl ether and diethyl ether, International Journal of Thermal Sciences.

Patel C. D., Patel H. J., Patel H. M., Patel T. M. \& Rathod G. P., (2014), Evaluation of Engine Performance and Emission by Using Diesel and It's Blend with Tyre Pyrolysis Oil, and DEE on Four Stroke Single Cylinder Diesel Engine, International Journal for Research in Technological Studies.

M. R. Kamesh, D. Madhu and C. P. S. Prakash, (2014), Introduction of Blended Pilot Fuel to Enrich the Charge in a CI Engine, International Journal of Thermal Technologies.

Dara S. S. \& Umare S. S., (2014), A Textbook of Engineering Chemistry, S. Chand \& Company Ltd., New Delhi, Chap.2.

http://www.che.cemr.wvu.edu/publications/projects dee/ dee- a.pd, (visited 20 Dec.2015),

http://www.afdc.energy.gov/pdfs/dee.pdf(visited15Dec.201 5). 